\title{
Depression literacy among people living with HIV/AIDS in a Nigerian tertiary hospital
}

\author{
Deborah O. Aluh ${ }^{1}$, Obinna C. Anyachebelu², Abdulmuminu Isah ${ }^{1}$ \\ ${ }^{1}$ Clinical Pharmacy and Pharmacy Management, University of Nigeria Nsukka, Nigeria \\ ${ }^{2}$ Chukwuemeka Ojukwu Odimegwu Teaching Hospital, Nigeria
}

\begin{abstract}
Introduction: Depression is the most prevalent psychiatric comorbidity linked with human immunodeficiency virus (HIV) infection. This study aimed to assess the depression literacy, risk perception, and preferred source of help for depression among people living with HIV/acquired immunodeficiency syndrome (AIDS).

Material and methods: It was a cross-sectional descriptive survey. The D-lit questionnaire was used to assess depression literacy. Data analyses were completed with IBM Statistical Product and Services Solution for Windows, version 21.0. Descriptive analyses were performed to characterize the survey sample. Open-ended responses were grouped based on the similarity of thematic content and frequencies/percentages reported. Kruskal-Wallis and Mann-Whitney tests were carried out to compare independent variables, with significance set at $p<0.05$.

Results: A total of 188 out of 351 questionnaires distributed were completed (response rate, 53.71\%). About $53.2 \%$ of the respondents $(n=100)$ had depression knowledge scores less than the average score of $10.54 \pm 2.032$. Males had statistically significant higher depression literacy scores than females. The majority of respondents reported that they would seek help from their primary care physician $(47.9 \%, n=90)$, while less than one-fifth of them opted to seek help from a psychologist $(18.6 \%$, $n=35)$. A greater proportion of males recommended seeking help from a psychologist compared to females $(25.0 \%, n=12$ vs. $16.4 \%, n=23)$.

Conclusions: The people living with HIV/AIDS surveyed had a poor knowledge of depression and the majority felt they were not at risk of getting depressed. A majority of them reported they would seek help from their primary care physician, therefore underscoring the importance of routine depression screening among this population.
\end{abstract}

HIV AIDS Rev 2021; 20, 2: 121-126

DOI: https://doi.org/10.5114/hivar.2021.107218

Key words: PLWHA, depression, mental health literacy, help-seeking, knowledge, psychologists.

\section{Introduction}

In 2018, about 38 million people were living with human immunodeficiency virus (HIV) [1]. Sub-Saharan Africa has the highest burden of HIV/acquired immunodeficiency syndrome (AIDS) globally, and the disease is currently the most

common cause of death in the region [2]. Almost 10\% of the global population of people living with HIV/AIDS (PLWHA) live in Nigeria [3]. Although HIV prevalence among adults in Nigeria is not high (1.5\%), but due to its enormous population, it translates to about 1.9 million people [4]. Mental health of PLWHA has received increasing attention in recent

Article history:

Received: 03.05.2020

Received in revised form: 10.09.2020

Accepted: 08.10.2020

Available online: 30.06 .2021
International Journal of HIV-Related Problems

HIV \& AIDS

R e vi e w 
years, and depression has been reported to be common among PLWHA. Depression is presently the most common cause of disability in the world [5], and nearly $4.4 \%$ of the global population are reported to be living with depression [6] A recent study by the World Bank showed that one in five Nigerians was depressed, and depression was associated with a lower labor force participation [7].

Mental health and HIV/AIDS are intricately associated [8]. Depression is the most prevalent psychiatric comorbidity linked with HIV infection [9]. HIV and depression have been shown to have a bidirectional relationship, in which depression can increase the risk of getting HIV-infected and be triggered by a diagnosis of HIV infection in people living with the virus [10-13]. Factors associated with developing clinical depression in PLWHA include neurobiological changes connected with the sustained presence of human immunodeficiency virus in the central nervous system (CNS), response to social stigma, coping with the possibility of illness and death, bearing the burden of lifelong antiretroviral therapy and its side-effects, and comorbid illnesses [14, 15]. Depression has been consistently shown to negatively impact HIV-infected patients, significantly decreasing their adherence to antiretroviral treatment, quality of life, treatment outcome, and functionality $[16,17]$. The prevalence of depression in PLWHA has been reported to be greater in developing countries compared to developed countries [18]. A study by Chikezie et al. in Nigeria revealed that depression was five times more prevalent among PLWHA compared to general population [19]. The severity of depression was also reported to be greater in PLWHA compared to non-infected populations [19]. The higher tendency for depression among PLWHA points to the need for mental health awareness and improved help-seeking behaviors among these individuals.

Mental health literacy (MHL) has been defined by Jorm and colleagues as "the knowledge and beliefs about mental disorders, which aid their recognition, management, or prevention" [20]. This definition serves as the basis for the premise that the conceptual models used by individuals to understand and explain mental health illnesses, influence their help-seeking behaviors for psychiatric symptoms, preferred treatment options, and stigmatization of patients [21-23]. Therefore, it is important to assess the MHL of PLWHA, since it has been shown to influence varied population's mental health-related choices, particularly their help-seeking for psychiatric symptoms [21].

MHL of depression among PLWHA is of interest, since depression is about 4-5 times [19,24] more prevalent in this population compared to the general population. A baseline study on mental health literacy of PLWHA is an important precursor for developing skills that will promote their psychological well-being. Although, there have been previous assessments of mental health literacy among different populations globally [24-28], no study has comprehensively examined the knowledge of depression among PLWHA, indicating the need for the present study. The present study intended to assess knowledge, risk perception, and help-seeking behaviors towards depression among this vulnerable population.

\section{Material and methods}

\section{Study design}

The study was a cross-sectional descriptive survey carried out in the antiretroviral therapy (ART) clinic of Chukwuemeka Odumegwu Ojukwu University Teaching Hospital (COOUTH) between February and April 2019. COOUTH is a tertiary healthcare facility, which offers extensive HIV treatment services, and is located in Anambra State, SouthEastern Nigeria.

\section{Study sample}

A minimum sample size of 351 was obtained using Raosoft sample size calculator [25], given that an estimated 4,000 people were enrolled in the ART clinic at the time of the study. All registered patients older than 9 years old were eligible to be enrolled in the study. Study participants were randomly selected from the attendance register, and were recruited for the study after the receipt of care to ensure that they did not feel obliged to participate in the survey. Willing participants signed an informed consent form and were recruited. No incentives were given for being part of the research study.

The ethical approval for this study was obtained from ethical committee of the Chukwuemeka Ojukwu Odumegwu University Teaching Hospital, while a written informed consent was obtained from all the participants.

\section{Data collection and analysis}

Depression literacy questionnaire (D-Lit) developed by Griffith et al. was used in this study [26], and permission to use D-Lit was sought and obtained from the lead developer. The instrument used in the research was organized into three sections: section A sought information on sociodemographics, section B contained questions in D-Lit, while section C comprised open-ended questions on risk perception and preferred source of help. D-Lit items include depression symptoms, management, treatment, and duration as well as differentiation between depression and other mental illnesses. For each respondent, the overall depression literacy scores were calculated as a sum of correct answers ranging from 0 up to a maximum score of 22. Higher scores indicated higher depression literacy. The mean average score obtained in the current study was used as a cut-off to make the tool relevant in the study setting, since the instrument was originally developed for elite athletes [27]. The D-Lit was pre-tested before the survey on 20 patients who were not part of the study population, and had a good internal consistency with a Cronbach $\alpha$ of 0.69 . Pre-test data were excluded from the final survey data. Data were analyzed using IBM Statistical Product and Services Solution for Windows, version 21.0. Descriptive analyses were performed to characterize the survey sample. Open-ended responses were grouped based on the similarity of thematic content and frequencies/ 
percentages reported. Kruskal-Wallis and Mann-Whitney tests were carried out to compare independent variables, with statistical significance set at $<0.05$.

\section{Results}

A total of 188 out of 351 questionnaires were completed (response rate, 53.71\%). About three-quarters of the respondents were females $(74.5 \%, n=140)$ and were mostly between $21-30$ years $(45.2 \%, n=85)$. A majority of them had tertiary education $(55.9 \%, n=105)$, and about half of them were single $(49.5 \%, n=93)$. Nearly half of them were employed $(47.9 \%, n=90)$, while about a quarter of them were students $(22.9 \%, n=43)$ (Table 1$)$.

The mean D-Lit score was $10.54 \pm 2.032$. About $53.2 \%$ of the respondents $(n=100)$ had depression knowledge scores less than the average score of 10.54. A greater proportion of male respondents reported being at a higher risk of depression (47.9\% vs. $39.3 \%$ ) compared to females. A greater proportion of males than females recommended seeking help from a psychologist $(25.0 \%$ vs. $16.4 \%)$ and counsellor ( $16.7 \%$ vs. $14.3 \%)$. These differences did not reach statistical significance. The majority of the respondents reported that they would seek help from their GP $(47.9 \%, n=90)$, while less than one-fifth of them opted to seek help from a psychologist $(18.6 \%, n=35)$ (Table 2). Depression literacy scores were statistically significantly different among respondents of different gender, educational level, and preferred source of help (Table 3). Approximately three-quarters of the surveyed respondents reported that antidepressants are addictive $(71.7 \%$, $n=101)$. Almost all the respondents reported counselling as effective as cognitive behavioral therapy for depression (95.4\%, $n=145)$. The most frequently recognized symptom of depression by the respondents was loss of confidence and poor self-esteem $(88.3 \%, n=136)$.

\section{Discussion}

There were more females than males respondents in this study. In Nigeria, HIV infection is more prevalent in females than males across all age group, except for the 35-39 years and 40-44 years age groups [28]. Furthermore, a report from UNAIDS showed that about $68 \%$ of adult women living with HIV were on ART, compared to $37 \%$ of adult men [29]. More than three-quarters of the respondents were between 21 and 40 years old.

Males were more knowledgeable about depression than females. This is in contrast with other studies among other study populations, where females were shown to have a higher knowledge of depression [30-32]. This difference could be attributed to peculiarity of the study population, in which males were underrepresented, and males at ART clinic maybe over-representative of 'health-conscious' men. The difference may also be attributed to differences in study instruments. Higher depression literacy in females has been explained by a higher prevalence of the disorder among them $[33,34]$.
Table 1. Socio-demographic characteristics of study respondents

\begin{tabular}{|c|c|}
\hline Variable & $n(\%)$ \\
\hline \multicolumn{2}{|l|}{ Gender } \\
\hline Male & $48(25.5)$ \\
\hline Female & $140(74.5)$ \\
\hline \multicolumn{2}{|l|}{ Age (years) } \\
\hline $9-20$ & $13(6.9)$ \\
\hline $21-30$ & $85(45.2)$ \\
\hline $31-40$ & $64(34.0)$ \\
\hline $41-50$ & 19 (10.1) \\
\hline 51 and above & $7(3.7)$ \\
\hline \multicolumn{2}{|l|}{ Educational level } \\
\hline Non-formal & $8(4.3)$ \\
\hline Primary & $11(5.9)$ \\
\hline Secondary & $64(34.0)$ \\
\hline Tertiary & 105 (55.9) \\
\hline \multicolumn{2}{|l|}{ Marital status } \\
\hline Single & $93(49.5)$ \\
\hline Married & $77(41.0)$ \\
\hline Widowed & $15(8.0)$ \\
\hline Divorced & $3(1.6)$ \\
\hline \multicolumn{2}{|l|}{ Employment status } \\
\hline Employed & 90 (47.9) \\
\hline Unemployed & $50(26.6)$ \\
\hline Retired & $5(2.7)$ \\
\hline Student & 43 (22.9) \\
\hline
\end{tabular}

Table 2. The preferred sources of help for depression

\begin{tabular}{l|c}
\hline Source of help & $n(\%)$ \\
\hline Psychologist & $35(18.6)$ \\
\hline Pastor & $10(5.3)$ \\
\hline God & $12(6.4)$ \\
\hline Counsellor & $28(14.9)$ \\
\hline Friend & $3(1.6)$ \\
\hline Child & $3(1.6)$ \\
\hline Wife/ husband & $7(3.7)$ \\
\hline Primary care provider & $90(47.9)$ \\
\hline
\end{tabular}

Although women bear a greater burden of depression, it is a significant morbidity and mortality risk for men [29]. The higher prevalence of depression among females has also been attributed to biological predisposition and life events in women's life, such as childbearing $[35,36]$. Another possible reason for higher depression literacy in females is that women are more likely to discuss about depressive symptoms than men [30]. 
Table 3. Association between socio-demographic variables and depression literacy scores

\begin{tabular}{|c|c|c|}
\hline Grouping variable & $\begin{array}{l}\text { Kruskal-Wallis test } \\
\text { mean rank (D-lit) }\end{array}$ & $p$-value \\
\hline \multicolumn{3}{|l|}{ Educational level } \\
\hline Non-formal & 46.69 & \multirow[t]{4}{*}{$0.003^{*}$} \\
\hline Primary & 125.50 & \\
\hline Secondary & 84.05 & \\
\hline Tertiary & 100.43 & \\
\hline \multicolumn{3}{|l|}{ Age group } \\
\hline $9-20$ & 106.35 & \multirow[t]{5}{*}{0.406} \\
\hline $21-30$ & 98.32 & \\
\hline $31-40$ & 87.46 & \\
\hline $41-50$ & 81.76 & \\
\hline 51 and above & 112.21 & \\
\hline \multicolumn{3}{|l|}{ Marital status } \\
\hline Single & 100.24 & \multirow[t]{4}{*}{0.320} \\
\hline Married & 88.64 & \\
\hline Widowed & 79.03 & \\
\hline Divorced & 111.17 & \\
\hline \multicolumn{3}{|l|}{ Employment status } \\
\hline Employed & 91.24 & \multirow[t]{4}{*}{0.614} \\
\hline Unemployed & 90.51 & \\
\hline Retired & 99.40 & \\
\hline Student & 103.42 & \\
\hline \multicolumn{3}{|c|}{ Preferred source of help } \\
\hline Psychologist & 108.01 & \multirow[t]{8}{*}{$0.016^{*}$} \\
\hline Pastor & 116.80 & \\
\hline God & 94.29 & \\
\hline Counsellor & 97.11 & \\
\hline Friend & 129.17 & \\
\hline Child & 155.50 & \\
\hline Wife/husband & 118.07 & \\
\hline Doctor & 79.95 & \\
\hline Grouping variable & $\begin{array}{l}\text { Mann-Whitney } \\
\text { mean rank (D-lit) }\end{array}$ & $p$-value \\
\hline \multicolumn{3}{|l|}{ Gender } \\
\hline Male & 108.16 & \multirow[t]{2}{*}{$0.034^{\star}$} \\
\hline Female & 89.11 & \\
\hline \multicolumn{3}{|l|}{ Risk perception } \\
\hline Not at risk & 95.82 & \multirow[t]{2}{*}{0.582} \\
\hline No & 91.46 & \\
\hline
\end{tabular}

In the present study, education was significantly associated with depression literacy scores. This is consistent with findings from a recent Iranian study, where there was a correlation between level of education and mental health literacy [37].
Higher education translates to increased access to health information, exposure to a bigger social network, and higher chances of learning about mental health [38]. Lower educational levels were linked to decreased help-seeking, less knowledge about mental health, and increased psychological distress for both genders [39-41]. Study findings provide credence to the construct that disease literacy is necessary for treatment engagement [42]. Friends and family are often the preferred sources of help over health professionals for depression [43, 44]. In this study however, a majority of the study sample responded that they would seek help from their primary care physician. Again, this difference may be explained by the peculiarity of their disease, which necessitates routine hospital visits and physician appointments. This underscores the importance of routine depression screening by primary care providers among this vulnerable population. While women are known to experience higher rates of depressive symptoms than men, poor help-seeking behaviors among men pose an important concern [36]. Surprisingly, a greater proportion of males than females reported that they would seek help from a mental health professional (psychologist/psychiatrist). This finding is different from previous studies, where more females than males recommended formal help-seeking for depressed individuals $[45,46]$. However, this concurs with findings from a Nigerian study, in which more male teachers recommended mental health professionals for a vignette character with symptoms of depression [47]. A direct comparison between the cited studies above and the present may not be accurate, as the present study sought to know where the participants would seek help for themselves and not for someone else, as in the above-mentioned studies.

More than half of the respondents felt that they were not at risk of getting depressed. A greater proportion of male respondents surveyed felt they were at risk of depression. This finding may not be unrelated to the fact that they were more knowledgeable about depression in this study, and therefore knew that they were in fact at risk of being depressed. One way to mitigate the negative impact of depression on outcomes in PLWHA is improving their depression literacy to promote early detection and help-seeking among this population. Several studies have established the association between HIV infection and depression; however, this is the first attempt to learn what PLWHA know about depression. The relatively small sample size of participants limits the generalizability of the study findings. There is also the possibility of chanced answers. Furthermore, there could be a difference between responders and non-responders leading to a selection bias. Depression knowledge is an essential part of preventing the debilitating effects of depression, which coexist with chronic conditions, such as HIV infection. Integrating mental health literacy tools into HIV care can improve early detection and appropriate referrals in this population.

\section{Conclusions}

The PLWHA surveyed had a poor knowledge of depression, and a majority of them reported that they would 
seek help from their primary care provider. More than half of the participants felt they were not at risk of being depressed. Poor mental health negatively impacts on the quality of life among PLWHA. More studies are needed to understand how coping and social support relate to depression and anxiety in this population to guide the development of appropriate mental health treatment and support services.

\section{Conflict of interest}

The authors declare no conflict of interest with respect to the research, authorship, and/or publication of this article.

\section{References}

1. Global HIV \& AIDS statistics - 2019 fact sheet | UNAIDS [Internet]. Available from: https://www.unaids.org/en/resources/factsheet (Accessed: 7.10.2019).

2. GBD 2016 Causes of Death Collaborators. Global, regional, and national age-sex specifc mortality for 264 causes of death, 1980-2016 a systematic analysis for the Global Burden of Disease Study 2016. Lancet 2017; 390: 1151-1210.

3. UNAIDS 2014. The Gap Report 2014. Jt United Nations Program HIV/AIDS. 2014.

4. AIDSinfo | UNAIDS [Internet]. Available from: http://aidsinfo unaids.org/ (Accessed: 7.10.2019).

5. Friedrich MJ. Depression is the leading cause of disability around the world. JAMA 2017; 317: 1517

6. UN health agency reports depression now 'leading cause of disability worldwide' | UN News [Internet]. Available from: https:// news.un.org/en/story/2017/02/552062-un-health-agency-reports-depression-now-leading-cause-disability-worldwide\#.WLRpQBB3xBw (Accessed: 7.10.2019)

7. How Depression Affects Welfare in a Context of Conflicts [Internet]. Available from: http://documents.worldbank.org/curated/ en/607301516882442320/pdf/122976-eMBeD-Nigeria-DepressionBrief.pdf (Accessed: 4.07.2019).

8. Aguocha CM, Uwakwe RU, Duru CB, et al. Prevalence and sociodemographic determinants of depression among patients attending HIV/AIDS Clinic in a Teaching Hospital in Imo State, Nigeria. Am J Med Sci Med 2016; 3: 106-112 [Internet]. Available from: http:// pubs.sciepub.com/ajmsm/3/6/4/ (Accessed: 7.10.2019).

9. Valente SM. Depression and HIV disease. J Assoc Nurses AIDS Care 2003; 14: 41-51.

10. Nanni MG, Caruso R, Mitchell AJ, Meggiolaro E, Grassi L. Depression in HIV infected patients: a review. Curr Psychiatry Rep 2015; 17: 530.

11. Chibanda D, Cowan FM, Healy JL, Abas M, Lund C. Psychological interventions for Common Mental Disorders for People Living With HIV in Low- and Middle-Income Countries: Systematic review. Trop Med Int Health 2015; 20: 830-839.

12. Niu L, Luo D, Liu Y, Silenzio VMB, Xiao S. The mental health of people living with HIV in China, 1998-2014: a systematic review. PLoS One 2016; 11: e0153489.

13. Shubber Z, Mills EJ, Nachega JB, et al. Patient-reported barriers to adherence to antiretroviral therapy: a systematic review and metaanalysis. PLoS Med 2016; 13: e1002183.

14. Phillips KD, Sowell RL, Rojas M, Tavakoli A, Fulk LJ, Hand GA. Physiological and psychological correlates of fatigue in HIV disease. Biol Res Nurs 2004; 6: 59-74.

15. Schuster R, Bornovalova M, Hunt E. The influence of depression on the progression of HIV: direct and indirect effects. Behav Modif 2012; 36: 123-145.

16. Leserman J. Role of depression, stress, and trauma in HIV disease progression. Psychosom Med 2008; 70: 539-545.
17. Richards D. Prevalence and clinical course of depression: a review. Clin Psychology Rev 2011; 31: 1117-1125.

18. Tung MY, Gee ML, Guan NC, et al. Identifying depression among the human immunodeficiency virus (HIV) patients in University Malaya Medical Centre, Kuala Lumpur, Malaysia. ASEAN Journal of Psychiatry 2009; 10: 1-13.

19. Chikezie U, Otakpor A, Kuteyi O, James B. Depression among people living with human immunodeficiency virus infection/acquired immunodeficiency syndrome in Benin City, Nigeria: a comparative study. Niger J Clin Pract [Internet] 2013; 16: 238. Available from: http:// www.ncbi.nlm.nih.gov/pubmed/23563469 (Accessed: 7.10.2019).

20. Jorm AF, Korten AE, Jacomb PA, Christensen H, Rodgers B, Pollitt $P$. "Mental health literacy": a survey of the public's ability to recognise mental disorders and their beliefs about the effectiveness of treatment. Med J Aust 1997; 166: 182-186.

21. Furnham A, Swami V. Mental health literacy: a review of what it is and why it matters. Int Perspect Psychol Res Pract Consult 2018; 7: 240-257.

22. Kurihara T, Kato M, Sakamoto S, Reverger R, Kitamura T. Public attitudes towards the mentally ill: a cross-cultural study between Bali and Tokyo. Psychiatry Clin Neurosci 2000; 54: 547-552.

23. Kermode M, Bowen K, Arole S, Pathare S, Jorm AF. Attitudes to people with mental disorders: a mental health literacy survey in a rural area of Maharashtra, India. Soc Psychiatry Psychiatr Epidemiol 2009; 44: 1087-1096.

24. Nacher M, Adriouch L, Godard Sebillotte C, et al. Predictive factors and incidence of anxiety and depression in a cohort of HIV-positive patients in French Guiana. AIDS Care 2010; 22: 1086-1092.

25. Sample Size Calculator by Raosoft, Inc. [Internet]. Available from: http://www.raosoft.com/samplesize.html (Accessed: 15.01.2020).

26. Depression Literacy Questionnaire (D-Lit) $\mid$ Research School of Population Health [Internet]. Available from: https://rsph.anu.edu. $\mathrm{au} / \mathrm{research} /$ tools-resources/depression-literacy-questionnaired-lit (Accessed: 12.10.2019).

27. Depression Literacy Questionnaire (D-Lit) $\mid$ Research School of Population Health [Internet]. Available from: https://rsph.anu.edu. $\mathrm{au} / \mathrm{research} /$ tools-resources/depression-literacy-questionnaired-lit (Accessed: 7.10.2020).

28. Awofala AA, Ogundele OE. HIV epidemiology in Nigeria. Saudi J Biol Sci 2018; 25: 697-703.

29. Nigeria | UNAIDS [Internet]. Available from: https://www.unaids. org/en/regionscountries/countries/nigeria (Accessed: 25.10.2019).

30. Townsend L, Musci R, Stuart E, et al. Gender differences in depression literacy and stigma after a randomized controlled evaluation of a universal depression education program. J Adolesc Health 2019; 64: 472-477.

31. Reavley NJ, McCann TV, Jorm AF. Mental health literacy in higher education students. Early Interv Psychiatry 2012; 6: 45-52.

32. Ghadirian L, Sayarifard A. Depression literacy in urban and suburban residents of Tehran, the capital of Iran; recognition, help seeking and stigmatizing attitude and the predicting factors. Int J Prev Med 2019; 10: 134

33. Bhattarai N, Charlton J, Rudisill C, Gulliford MC. Prevalence of depression and utilization of health care in single and multiple morbidity: a population-based cohort study. Psychol Med 2013; 43: 1423-1431.

34. Kessler RC, Avenevoli S, Costello EJ, et al. Prevalence, persistence, and sociodemographic correlates of DSM-IV disorders in the National Comorbidity Survey Replication Adolescent Supplement. Arch Gen Psychiatry 2012; 69: 372-380.

35. Hatzimanolis A, Vitoratou S, Mandelli L, et al. Potential role of membrane-bound COMT gene polymorphisms in female depression vulnerability. J Affect Disord 2013; 148: 316-322.

36. Wisner KL, Sit DKY, McShea MC, et al. Onset timing, thoughts of self-harm, and diagnoses in postpartum women with screen-positive depression findings. JAMA Psychiatry 2013; 70: 490-498. 
37. Bahrami MA, Bahrami D, Chaman-Ara K. The correlations of mental health literacy with psychological aspects of general health among Iranian female students. Int J Ment Health Syst [Internet] 2019; 13: 59. Available from: https://ijmhs.biomedcentral.com/ articles/10.1186/s13033-019-0315-6 (Accessed: 27.10.2020).

38. Ibrahim N, Amit N, Shahar S, et al. Do depression literacy, mental illness beliefs and stigma influence mental health help-seeking attitude? A cross-sectional study of secondary school and university students from B40 households in Malaysia. BMC Public Health 2019; 19 (Suppl 4): 544

39. Mendenhall AN, Frauenholtz S. Mental health literacy: SocialWork's role in improving public mental health. Social Work (United States). 2013.

40. Ojeda VD, McGuire TG. Gender and racial/ethnic differences in use of outpatient mental health and substance use services by depressed adults. Psychiatr Q Fall 2006; 77: 211-222.

41. Khlat M, Legleye S, Sermet C. Factors influencing report of common mental health problems among psychologically distressed adults. Community Ment Health J 2014; 50: 597-603.

42. Lopez V, Sanchez K, Killian MO, Eghaneyan BH. Depression screening and education: An examination of mental health literacy and stigma in a sample of Hispanic women. BMC Public Health 2018; 18: 646.

43. Rickwood DJ, Deane FP, Wilson CJ. When and how do young people seek professional help for mental health problems? Med J Australia 2007; 187 (Suppl 7): S35-39.

44. Rickwood DJ, Braithwaite VA. Social-psychological factors affecting help-seeking for emotional problems. Soc Sci Med 1994; 39: 563-572.

45. Klineberg E, Biddle L, Donovan J, Gunnell D. Symptom recognition and help seeking for depression in young adults: A vignette study. Soc Psychiatry Psychiatr Epidemiol 2011; 46: 495-505.

46. Wendt D, Shafer K. Gender and Attitudes about Mental Health Help Seeking: Results from National Data. Health Soc Work [Internet] 2016; 41: e20-28. Available from: https://academic.oup.com/ hsw/article-lookup/doi/10.1093/hsw/hlv089.

47. Aluh DO, Dim OF, Anene-Okeke CG. Mental health literacy among Nigerian teachers. Asia-Pacific Psychiatry [Internet]. 2018 Sep 3; e12329. Available from: http://doi.wiley.com/10.1111/appy.12329 (Accessed: 5.08.2018). 